\title{
Fatores determinantes da aceitação de mercado da tecnologia do banco digital no contexto brasileiro

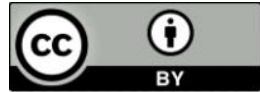

\section{DETERMINANT FACTORS OF MARKET ACCEPTANCE OF THE DIGITAL BANKING TECHNOLOGY IN THE BRAZILIAN CONTEXT}

Lis Borges, Universidade Federal da Bahia, Brazil, (borgeslis@gmail.com)

Paulo Figueiredo, Universidade Federal da Bahia, Brazil, (paulo_s_figueiredo@hotmail.com)

Francisco Uchoa Passos, Centro Universitário Senai Cimatec, Brazil, (uchoapassos@gmail.com)

Ernani Marques dos Santos, Universidade Federal da Bahia, Brazil, (ernanims@gmail.com)

\section{RESUMO}

Este trabalho teve como objetivo estudar os fatores que influenciam a intenção de uso dos bancos digitais pelos potenciais consumidores no Brasil. O referencial teórico fundamenta-se no Modelo de Aceitação da Tecnologia (TAM). Muito embora já tenham sido realizados estudos semelhantes sobre este tema, em vários contextos e em outros países, este é um estudo pioneiro no contexto brasileiro, sobre este tema específico, utilizando o referido modelo. Por meio de uma abordagem descritiva e quantitativa, dados foram coletados a partir de um questionário, em uma amostra não representativa de 113 potenciais usuários. A análise dos dados foi feita através de regressão linear multivariada. Os resultados indicaram que a percepção de utilidade, a percepção de satisfação, percepção de segurança e privacidade, bem como a renda afetam positivamente a intenção de uso do banco digital e são os fatores mais significativos para a amostra estudada. Além da contribuição acadêmica para os estudos sobre aceitação de tecnologias bancárias, as conclusões contribuem para que os bancos digitais construam estratégias que agreguem valor à percepção desses fatores pelos potenciais consumidores de produtos bancários.

Palavras-chave: Aceitação de mercado; Aceitação de tecnologia; Banco digital; Marketing; Brasil. 


\section{ABSTRACT}

This study aimed to evaluate factors that influence the intention of using digital banks by potential consumers in Brazil. The theoretical framework is based on the Technology Acceptance Model (TAM). Although similar studies on this subject have already been conducted, in various contexts and in other countries, this is a pioneering study on this specific topic in the Brazilian context, using the aforementioned model. By means of a descriptive and quantitative approach, data were collected using a questionnaire, in a nonrepresentative sample of 113 potential users. Data analysis was performed using multivariate linear regression. The results indicated that the perception of utility, the perception of satisfaction, the perception of security and privacy, as well as income, positively affect the intention to use the digital bank and are the most significant factors for the studied sample. In addition to the academic contribution to studies focused on the acceptance of banking technologies, the conclusions contribute to enabling digital banks to build strategies that add value to the perception of these factors by potential consumers of banking products.

Keywords: market acceptance; marketing; Technology acceptance; digital bank; Brazil.

\section{INTRODUÇÃO}

Durante muitos anos o setor financeiro se beneficiou da baixa concorrência devida à estrutura de mercado concentrada e de fatores ligados à regulamentação (Claessens \& Laeven, 2005; Clerides, Delis, Kokas, 2015). Contudo, os desafios impostos pelas novas tecnologias digitais têm despertado a necessidade de mudanças, tanto em qualidade (Filgueiras\& D'Amorim, 2019) quanto em variedade de serviços. Nesse contexto, não identificar tendências tecnológicas e novas necessidades dos consumidores, a tempo, pode resultar em perda de competitividade ou mesmo extinção.

Seguindo as novas tendências do setor financeiro quanto ao uso de tecnologias digitais, novos modelos de negócio têm surgido e os bancos passaram a enfrentar a competição de novos entrantes no mercado. As fintechs (abreviação de tecnologia financeira em inglês) surgem como novas soluções que demonstram um desenvolvimento de inovação 
incremental ou radical / disruptiva de aplicativos, processos, produtos ou modelos de negócios na indústria de serviços financeiros (Alt \& Purschmann, 2012; Chuang,Liu \& Kao, 2016). No Brasil, segundo levantamento da Fintech lab, até agosto de 2020 já existiam 771 fintechs, com um crescimento de $28 \%$ em relação a 2019 (FINTECHLAB, 2020). Essas iniciativas representam uma ameaça aos bancos tradicionais, que buscam estratégias de modificação para se aproximarem do modelo das fintechs, tendo a vantagem de possuírem uma base consolidada de clientes rentabilizados, mas com o desafio de adaptar estruturas custosas. O banco digital surge como uma estratégia dos bancos tradicionais de implantar um novo modelo de negócio, propondo iniciativas que aliam tecnologias digitais a serviços financeiros e inova na experiência do cliente (Larsson \&Viitaoja, 2017; Cook, 2017; Mbama \& Azepue, 2018).

No Brasil, uma das primeiras iniciativas de implantar um modelo de negócio bancário sem agências e com atendimento remoto ocorreu em 2000. De acordo com Veiga e Oliveira (2006), a iniciativa foi inspirada nos bancos Cortal da França e First Direct da Inglaterra, e o primeiro banco digital brasileiro recebeu o nome de Banco l. net. Contudo, em 2004 o banco encerrou suas atividades, sendo adquirido pelo seu acionista Unibanco, que absorveu seus 72 mil clientes (Jornal de Negócios, 2019).

Apesar de muitas mudanças tecnológicas terem ocorrido desde a primeira inciativa brasileira de banco digital no início dos anos 2000, a acessibilidade dos brasileiros às tecnologias bancárias possui um caminho a percorrer em comparação a outros países. De acordo com o mais recente relatório sobre inclusão financeira, elaborado pelo Banco Mundial (Demirguc-Kant et al, 2017), em 2017, 69\% dos adultos em todo o mundo possuíam uma conta bancária. Em economias de alta renda, 94\% da população adulta possui conta bancária e, destes, $91 \%$ realizam operações em meios digitais. Nas economias em desenvolvimento, 63\% dos adultos tem conta em banco e $70 \%$ deles usam a conta para operações digitais. $O$ 
Banco Central analisou esses dados abertos para o Brasil e divulgou que $70 \%$ dos brasileiros possuem conta, percentual abaixo, porém próximo do apresentado pelos demais países que compõem o BRICS, como a Rússia, Índia e China. Apenas $12,9 \%$ dos brasileiros fizeram uso da internet ou celular para acessar contas e o percentual de pessoas que declararam ter feito ou recebido um pagamento digital foi de 57,9\%. Comparado aos países da OCDE, esse valor foi de 92,1\% (Banco Central Do Brasil, 2017).

As novas tecnologias (Ross \& Sebastian, 2017), comportamento do consumidor (Kotler; Kartajaya \& Setiawan, 2017) e uma condição regulatória mais favorável (Banco Central Do Brasil, 2016) fazem parte do contexto atual, e contribuíram para o recente crescimento da disponibilidade de produtos e serviços financeiros e adesão ao modelo de banco digital. Porém, ainda existe muito que expandir, e diversos podem ser os fatores que estão limitando esse movimento. Daí a importância de pesquisar os determinantes da aceitação de tecnologias digitais pelos clientes no contexto recente, quando o uso das referidas tecnologias está mais presente no cotidiano das pessoas. Faz-se necessário testar se há, de fato, uma maior propensão da população em aceitar o banco digital e quais os fatores mais relevantes, para a adesão desses indivíduos.

Assim, a análise de aceitação de novas tecnologias no setor bancário, pela perspectiva do usuário, apesar de ser um tema bastante explorado, se faz necessária, neste momento, devido à alavancagem do relacionamento digital e ao consequente acirramento da concorrência entre os bancos digitais. O setor bancário é um dos que mais investem em Tecnologia da Informação (TI) no Brasil (Kovalczyk, 2017; Faria \& Maçada, 2011) e um dos primeiros a equiparar seu desenvolvimento em automação aos níveis estrangeiros (Diniz, 2004), portanto estudos sobre a aceitação de tecnologias digitais pelos clientes sempre terão interesse por parte do setor.

Os mais conhecidos modelos teóricos da literatura sobre o tema são o TAM (Technology Acceptance Model), a UTAUT (Unified Theory of 
Acceptance and Use of Technology), a IDT (Innovation Diffusion Theory) e suas variações. Em comum, esses modelos permitem identificar os principais fatores que determinam a aceitação de novas tecnologias (Pikkarainen et al., 2004; Im, Hong, \& Kang, 2011; Hanafizadeh, Keating \& Khedmatgozar, 2014; Shaikh \& Karjaluoto, 2015). Como explicam Bijker e Law (1992), as tecnologias não se alteram apenas sob a lógica interna, tecnológica ou científica, mas sua evolução ou mudança são pressionadas em direção a novas configurações devido, também, a fatores históricos, econômicos, políticos, psicológicos e sociológicos. Desta forma, o novo modelo de negócios proposto pelo banco digital não propõe apenas a não existência de agências, mas, também, a utilização de tecnologias digitais que promovam uma experiência de consumo diferenciada, com maior eficiência e agilidade na prestação de serviços, modificando não apenas os canais de relacionamento com clientes, mas a entrega de produtos mais personalizados.

A questão de pesquisa se define, portanto, como: "Quais fatores estão associados à intenção de uso dos bancos digitais no Brasil"?

Para solucionar tal questionamento, realizou-se um estudo exploratório, com amostra limitada, na cidade de Salvador, utilizando-se do modelo teórico TAM, na perspectiva do potencial usuário do banco digital.

\section{FUNDAMENTOS TEÓRICOS}

Apresentam-se, a seguir, os modelos teóricos mais utilizados sobre aceitação de tecnologia e justifica-se a opção pelo modelo TAM. Com base na literatura, são derivadas hipóteses.

\section{Teorias e Modelos de Aceitação de Tecnologia}

A aceitação de tecnologias é um tema que desperta bastante interesse dos pesquisadores há décadas, e diversas teorias e modelos de análise foram utilizados na busca de identificar seus determinantes. Os modelos mais 
utilizados nas pesquisas seguem três perspectivas: psicológica, tecnológica e social (Hanafizadeh, Keating \& Khedmatgozar, 2014). Os mais encontrados na literatura sobre bancos são: a Teoria da Difusão das Inovações, proposta por Everett M. Rogers em 1962; a Teoria da Ação Racional, introduzida por Icek Ajzen e Martin Fishbein em 1975; a Teoria do Comportamento Planejado, do autor Icek Ajzen, em 1985; o Modelo de Aceitação da Tecnologia (TAM), de Fred Davis, no ano de 1986; a Teoria Social Cognitiva, proposta por Albert Bandura, em 1989 e a Teoria Unificada de Aceitação e Uso da Tecnologia (UTAUT), de Venkatesh et al (2003), a qual trata de um esforço para unificar as 5 teorias anteriores. Essas teorias são estruturadas em diferentes constructos, e os autores usam, em seus estudos, uma dessas teorias de aceitação específica ou uma extensão dela. A tabela 1 apresenta uma breve revisão de alguns trabalhos que fizeram uso das mencionadas teorias.

Tabela 1-Síntese das Teorias de aceitação de tecnologia

\begin{tabular}{l|l|l}
\hline \multicolumn{1}{c|}{ Teoria } & \multicolumn{1}{c|}{ Autor (es)/ Ano } & \multicolumn{1}{c}{ Constructos } \\
\hline Teoria da Difusão das Inovações (IDT) & Rogers (1962) & $\begin{array}{l}\text { Vantagem relativa, } \\
\text { compatibilidade, }\end{array}$ \\
\hline Teoria da Ação Racional (TRA) & $\begin{array}{l}\text { Fishbein e Ajzen } \\
(1975)\end{array}$ & Atitude, norma subjetiva \\
\hline $\begin{array}{l}\text { Teoria do Comportamento } \\
\text { Planejado (TPB) }\end{array}$ & Ajzen (1980) & $\begin{array}{l}\text { Atitude, norma subjetiva, } \\
\text { controle comportamental } \\
\text { percebido }\end{array}$ \\
\hline $\begin{array}{l}\text { Teoria da Aceitação da Tecnologia } \\
\text { (TAM) }\end{array}$ & Davis (1986) & $\begin{array}{l}\text { Facilidade de uso percebida } \\
\text { e utilidade percebida }\end{array}$ \\
\hline Teoria Social Cognitiva (SCT) & Bandura (1989) & $\begin{array}{l}\text { Agência humana e } \\
\text { autoeficácia }\end{array}$ \\
\hline Teoria Unificada de Aceitação e Uso da & Venkatesh et al & $\begin{array}{l}\text { Expectativa de } \\
\text { performance, Expectativa } \\
\text { de esforço, Influência social } \\
\text { e Condições facilitadoras }\end{array}$ \\
\hline
\end{tabular}

Fonte: Elaboração própria a partir da revisão de literatura (2020)

De acordo com o trabalho de Hanafizadeh, Keating e Khedmatgozar (2014), quatro perspectivas de pesquisa inter-relacionadas definem o campo de estudos de serviços bancários pela Internet: (i) serviços bancários, que investigam e classificam os diversos serviços financeiros oferecidos no âmbito 
do internet banking; (ii) os canais de distribuição, que se dedicam a analisar as vantagens de diferentes canais de distribuição, os fatores que influenciam as estratégias de cada canal e a distribuição na prestação de serviços bancários; (iii) as perspectivas de bancos e gerentes de bancos, trazendo o ponto de vista institucional, cujos estudos apresentam as atitudes gerenciais na aceitação de tecnologias como a Internet e o valor estratégico na aplicação; e (iv) as perspectivas de clientes, que contemplam os estudos que se dedicam aos clientes bancários, suas atitudes, motivos, expectativas e crenças em relação à aceitação de tecnologias. É nesse último grupo de estudos que o presente trabalho se insere, em busca de trazer alguma contribuição.

Para a construção do nosso modelo conceitual, foram eleitas as variáveis do TAM, por tratar-se de um modelo amplamente testado e aplicado em estudos sobre aceitação de tecnologias por clientes do setor bancário, e influente para entender a aceitação dos sistemas de informação. Trata-se de um modelo bem-estabelecido e parcimonioso, e as críticas ao mesmo se referem justamente ao seu ponto forte, que é a parcimônia, (Lee, Kozar \& Larsen, 2003; Yiu, 2007; Pires \& Costa Filho, 2008; Cruz et al, 2010), o que leva alguns autores a incluir variáveis explicativas adicionais, complementando sua capacidade explicativa do fenômeno da aceitação de tecnologias.

\section{Modelo de Aceitação de Tecnologias (TAM)}

O Modelo de Aceitação da Tecnologia (Technology Acceptance Model - TAM) foi formulado por Davis (1989), com o objetivo de prever a aceitação e utilização de novas tecnologias da informação dentro das organizações. Em sua formulação, o autor argumenta que os potenciais usuários criam tendências motivacionais imediatamente após serem expostos a novas tecnologias da informação, antes mesmo que essas tendências resultem em um comportamento observável. A teoria se fundamenta em dois principais constructos: Percepção de Facilidade de Uso (PEOU - Perceived ease of 
Use), conceituada como o nível de crença do indivíduo em que o sistema não irá exigir esforço físico e mental; e a Utilidade Percebida (PU - Perceived Usefulness), que é o nível de crença do indivíduo de que o sistema irá aumentar sua performance no trabalho (DAVIS, 1986). O TAM tem sido um dos modelos mais influentes de aceitação da tecnologia (Charness \& Boot, 2016). O TAM serve como um framework geral bastante útil e é consistente com uma série de investigações sobre os fatores que influenciam a intenção de adultos em usar uma nova tecnologia (Braun, 2013).

Estudos mostram que o modelo TAM original é uma escala psicometricamente sólida e explica cerca de $47 \%$ da variância observada na atitude de consumidores com relação à aceitação de novas tecnologias (Thompson, Higgins \& Howell, 1994; Pires \& Costa Filho, 2008). Os autores Benbasat e Barki (2007) ressaltam que o TAM permanece sendo o referencial teórico mais consistente aplicado na área de aceitação de tecnologias e que as diversas tentativas teóricas posteriores sempre retornam aos constructos do modelo original. Houve vários outros estudos acadêmicos baseados no modelo TAM original, inclusive focados em aspectos da aceitação de tecnologias auxiliadas pela Internet, como por exemplo, Davis et al. (1989) e Davis e Venkatesh (2000). Desta forma, justifica-se a escolha aqui realizada, pela formulação de um modelo conceitual utilizando o TAM original para o presente estudo, em detrimento das versões subsequentes presentes na literatura pelos seguintes motivos: a) trata-se de um modelo parcimonioso, portanto, útil para uma primeira abordagem; b) mostrou-se um modelo adequado ao tamanho da amostra aqui selecionada, revelando as caraterísticas escolhidas e atendendo aos objetivos do estudo; c) possui um grau explicativo relevante, justificando quase metade das alterações da intenção de uso da nova tecnologia. Desta forma, o uso do TAM original significa que outros fatores contextuais, como por exemplo, o ecossistema da inovação e também o ciclo da inovação, não foram incluídos na análise (Jha \& Bose, 2016). 
Considerando o objetivo que norteia este trabalho, o trabalho de Pikkarainen et al (2004) forneceu as principais referências quanto aos constructos e medidas. Como adverte Bhatiasevi (2016), modelos populares extensivamente utilizados no passado estarão sujeitos a novas investigações, a fim de testar similaridades e diferenças dos resultados sob a perspectiva de outros contextos. É o que foi feito no presente estudo.

\section{Determinantes da Aceitação e Hipóteses}

A seguir, descrevem-se os determinantes selecionados na literatura e as hipóteses a serem testadas.

\section{Percepção de Facilidade de Uso (PEOU)}

A variável Percepção da Facilidade de Uso é originária do próprio modelo TAM e, de acordo com Davis (1986), representa o nível no qual o indivíduo acredita que o uso de um determinado sistema não exigirá grande esforço físico ou mental. Essa variável já foi amplamente utilizada em estudos sobre adoções de tecnologias em bancos, tais como internet banking e mobile banking e há muitas evidências na literatura de que a PEOU tem efeito significativo, direta ou indiretamente, na aceitação por parte de clientes (Pikkarainen et al, 2004; Cheng, Lam \& Yeung, 2006; Fernades \& Awamleh, 2006; Lee, 2009; Laukkanen, 2016; George, 2018). Segundo Laukkanen (2016), a PEOU pelo usuário evidencia o sentimento de que o provedor do serviço possui a habilidade de disponibilizar um sistema de qualidade. Desta forma, a primeira hipótese a testar é:

H1: A percepção de facilidade de uso tem efeito positivo na intenção de uso do banco digital.

\section{Percepção de Utilidade (PU)}

A utilidade percebida é definida por Davis (1986) como o nível em que um indivíduo acredita que o uso de um determinado sistema irá aumentar o seu desempenho no trabalho. É uma característica muito importante, que afeta a difusão de uma nova tecnologia tanto em ambientes 
organizacionais como não organizacionais, que é o caso de uso por clientes (Kishore \& Sequeira, 2016). Cabe ressaltar a importância observada em estudos anteriores sobre o mobile banking, que observaram que a utilidade percebida é um dos fatores mais relevantes entre os elementos que explicam a intenção de uso (Baptista \& Oliveira, 2015; Ha et al, 2012). Desta forma, espera-se que essas características aumentem as chances de uso do banco digital, de modo que se definiu, assim, a segunda hipótese:

H2: A percepção de utilidade tem um efeito positivo na intenção de uso do banco digital.

\section{Percepção de Satisfação}

Konradt, Christophersen e Schaeffer-Kuelez (2006) identificaram que a satisfação é um determinante quando se trata de aceitação da tecnologia, pois influencia nas intenções de recompra e reutilização. De acordo com Davis, Bagozzi e Warshaw (1992), a percepção de satisfação pode ser definida como o nível em que a atividade de usar uma interface computacional é percebido como agradável por si só. Pikkarainen et al (2004) identificaram que a Percepção de Satisfação é uma variável significativa para explicar a aceitação. Santouridis e Kyritsi (2014) defendem que as intenções de usar o internet banking poderiam ser negativamente afetadas por um alto nível de satisfação com o canal tradicional (as agências bancárias com estruturas físicas) mas que, em contraste com as agências bancárias tradicionais, uma vez que os caixas eletrônicos também constituem um canal de autoatendimento baseado na tecnologia, é muito provável que a satisfação com eles seja comprovadamente influenciada positivamente pelo internet banking. Com base nessas evidências, define-se a seguinte terceira hipótese:

H3: A percepção de satisfação tem um efeito positivo na intenção de uso do banco digital pelos consumidores.

\section{Percepção de Segurança e Privacidade}


As operações de comércio eletrônico envolvem uma percepção de risco, e o mobile banking também está nesse contexto (Malaquias \& Hwang, 2016). A percepção de risco foi considerada a principal barreira de aceitação do mobile banking na China (Laforet \& Li, 2005) e em diversos países integrantes da União Europeia (Fonseca, 2014). Os usuários potenciais de serviços bancários móveis vão usá-los efetivamente quando acreditarem que terão uma conclusão segura de suas transações; eles esperam uma maior proteção de informações pessoais e financeiras por parte do banco, na utilização desses canais (Bhatiasevi, 2016). Os clientes têm preocupações com segurança e privacidade, por isso esperam que as tecnologias móveis sejam confiáveis e que seus bancos as desenvolvam de forma segura (Zhou, 2012; Hanafizadeh Et Al, 2014). Portanto, a quarta hipótese definida no estudo é:

H4: A percepção de segurança e privacidade tem um efeito positivo na intenção de uso do banco digital pelos consumidores.

\section{Variáveis sóciodemográficas}

Diversos estudos sobre aceitação de serviços tecnológicos incluíram variáveis demográficas em suas análises, complementando a capacidade explicativa de modelos tradicionais, ao analisar os impactos dessas variáveis sobre constructos tecnológicos e comportamentais (Harrison; Rainer, 1992; Laukkanen 2016; Cruz et al, 2009; Malaquias \& Hwang, 2019). Em comum, esses estudos evidenciam que os indivíduos mais propensos em adotar novas tecnologias tendem a ser mais jovens, ter renda mais alta, ser do sexo masculino e com maior nível de instrução do que aqueles que não são tão suscetíveis a adotarem a tecnologia (Darian, 1987; Venkatraman, 1991; Karjalouto, Mattila \& Pento, 2002).

A renda familiar foi apontada em estudos anteriores com efeito positivo sobre a aceitação de serviços bancários pela internet (Karjalouto, Mattila \& Pento, 2002; Mauter, 2005). Os estudos de Meuter (2005) sugeriram que o aumento da renda poderia também aumentar as oportunidades de 
acesso a dispositivos mais atualizados (computadores e dispositivos móveis, por exemplo) e fornecer motivações para economia de tempo e praticidade no relacionamento com o banco.

Assim, focou-se na renda e, para melhor compreender a influência daquela característica na aceitação do banco digital, é estabelecida a quinta hipótese:

H5: Clientes com maior renda familiar têm maior intenção de uso do banco digital

Com relação à idade, os resultados indicam que os consumidores mais velhos têm maior resistência em adotar novas tecnologias (Harrison \& Rainer, 2012). Mohammadi (2015) identificou que os jovens poderiam ser menos resistentes em adotar novas tecnologias, como o mobile banking, devido ao fato de eles perceberem níveis mais baixos de risco na referida modalidade. Venkatesh et al.(2003) e Wang, Wu e Wang (2009) constataram que os mais jovens tendem a desenvolver níveis mais altos de confiança em serviços bancários móveis do que os entrevistados mais velhos. De acordo com Mattila et al. (2003), os clientes mais velhos apresentam uma percepção de dificuldade significativamente maior no uso de computadores e um nível mais alto de insegurança percebida quando comparados com os outros clientes. Com base nessas evidências, define-se a sexta hipótese a ser testada:

H6: A idade tem um efeito negativo na intenção de uso de banco digital.

Desta forma, a partir da definição do conjunto de hipóteses, formuladas com base na literatura explorada, busca-se testar e conhecer, dentre elas, quais as mais significativas e representativas para explicar a aceitação da tecnologia do banco digital.

\section{PROCEDIMENTOS METODOLÓGICOS}


Este estudo é, por natureza, quantitativo, uma vez que hipóteses foram testadas por meio de técnicas estatísticas. Quanto aos seus procedimentos, classifica-se como empírico e descritivo, pois se busca conhecer mais sobre um fenômeno, no caso, os fatores que influenciam a decisão de uso de bancos digitais, e os elementos de interpretação daquele fenômeno (Malhotra, 2012). Bancos digitais são delimitados, para os fins da pesquisa, como bancos que funcionam de forma online. Isso significa que praticamente tudo o que o cliente precisa pode ser feito virtualmente - da abertura da conta ao atendimento e pagamento de boletos. Desta forma, não se incluem bancos tradicionais que ofereçam mobile banking e internet banking (Carvalho, 2020).

A partir da revisão da literatura, foram selecionadas quatro variáveis explicativas, além da adição de duas variáveis demográficas de controle. As variáveis Percepção de Facilidade de Uso e Percepção de Utilidade pertencem ao TAM original. Foram incluídas as variáveis Percepção de Satisfação e a Percepção de Segurança e Privacidade por serem amplamente utilizadas na literatura e consideradas como relevantes. A inclusão das variáveis demográficas Idade e Renda familiar se justificam também pela utilização na literatura e a adição de potencial explicativo do modelo, conforme exposto na figura 1.

Figura 1. Modelo Conceitual de Análise

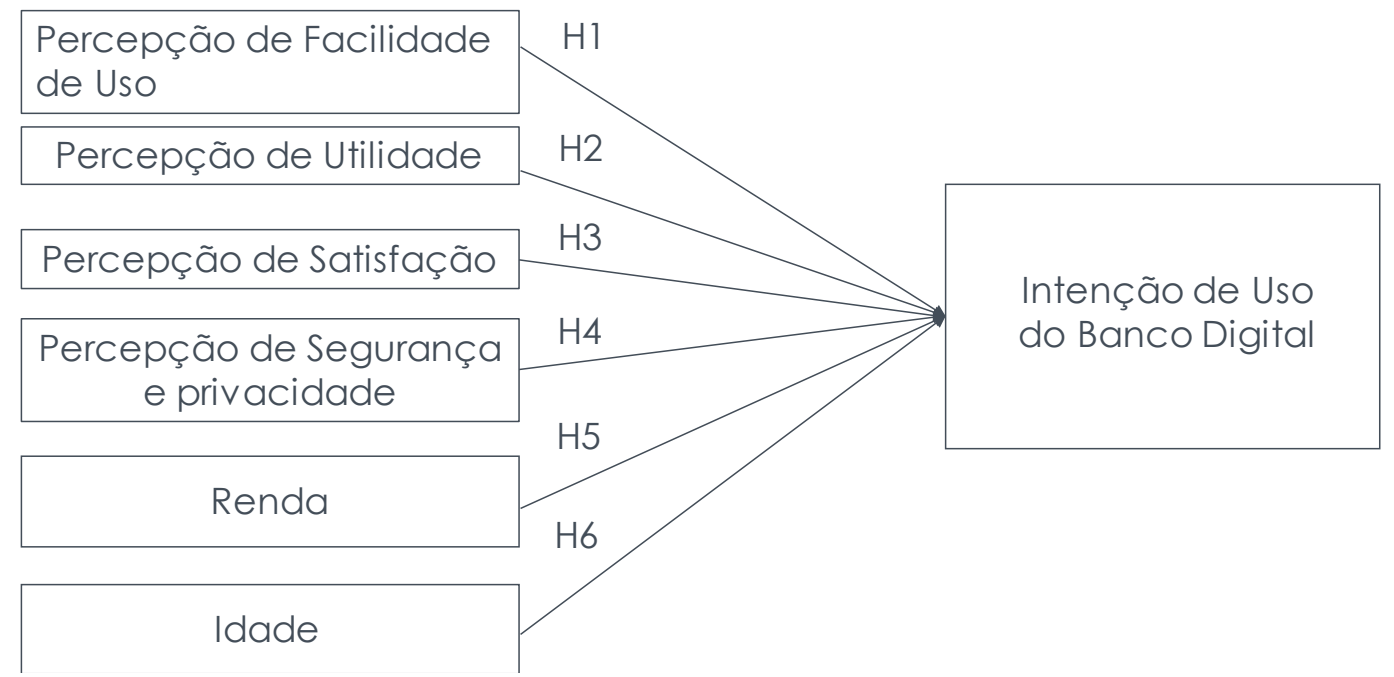


Fonte: adaptado de Pikkarainen et al (2004)

Como instrumento de coleta de dados, decidiu-se adotar o questionário desenvolvido por Pikkarainen et al (2004),por tratar-se de um instrumento amplamente testado e validado por meio de análise fatorial. O questionário emprega uma escala Likert de cinco pontos para codificar as respostas, e os intervalos variam de 1 (discordo totalmente) a 5 (concordo totalmente). A idade foi medida em anos e a renda familiar foi declarada em reais. De acordo com o procedimento do autor, os quatro fatores relacionados à intenção de uso foram tratados como variáveis independentes e agrupados em escalas. Técnicas estatísticas multivariadas são necessárias para estudos que visam explicar problemas complexos (Hair et al., 2016).

Foram feitos pré-teste e validação semântica do instrumento traduzido, com a participação de três doutores em Administração. A escala original foi traduzida para o português e retraduzida para o inglês, visando detectar inconsistências. O pré-teste e validação semântica visaram verificar o entendimento das perguntas, o significado dos construtos, e o tempo de resposta por parte dos três participantes. Pequenos ajustes foram realizados.

Foram coletados dados para possibilitar a realização de uma análise de regressão, testando as hipóteses que foram propostas. O objetivo da coleta de dados foi observar as relações estatísticas entre variáveis independentes e determinantes da intenção de uso do Banco Digital. Embora os itens do instrumento serem classificados em uma escala Likert, que é categórica, os fatores que compõem as variáveis independentes, com exceção de renda e idade, são médias aritméticas, variáveis contínuas, exigindo o uso de regressões não logísticas e lineares ordenadas (Gelman e Hill, 2007). A amostra foi definida pelos pesquisadores que selecionaram os participantes de acordo com sua acessibilidade (Vergara, 2013). É importante ressaltar que a abordagem escolhida para a amostra teve como objetivo aumentar o poder explanatório das conclusões e, portanto, utilizou-se uma análise de regressão com uma amostra adequada e não um estudo de caso, que não 
é favorável à generalização (Yin, 2011). Além disso, a presença de variação suficiente na amostra (consequência direta de um maior número de respondentes de diversas origens) é essencial para aumentar a validade dos resultados das regressões, uma vez que devem ser excluídas variáveis que exibem pouca variação, dentro da amostra coletada (Neter et al., 1996). Portanto, uma gama mais ampla de indivíduos é preferível para um determinado tamanho amostral. É claro que uma amostra maior é sempre desejável, mas o escopo deste estudo impossibilitou a obtenção de um número maior de participantes, o que é uma de suas limitações.

A tabela 2 descreve as variáveis aferidas pelo questionário, associadas a seus correspondentes constructos do modelo de análise.

Tabela 2: Constructos do modelo e suas variáveis 


\begin{tabular}{|c|c|c|}
\hline CONSTRUCTO & VARIÁVEL & FONTE \\
\hline \multirow{2}{*}{$\begin{array}{l}\text { Intenção de Uso } \\
\text { do Banco Digital }\end{array}$} & Caso eu tenha acesso ao Banco Digital, eu pretendo utilizá-lo & Venkatesh e Davis, 2000 \\
\hline & $\begin{array}{l}\text { Eu pretendo aumentar meu uso do Banco Digital no futuro, } \\
\text { vindo a adotá-lo }\end{array}$ & $\begin{array}{l}\text { Adaptada de Venkatesh } \\
\text { e Davis, } 2000\end{array}$ \\
\hline \multirow{6}{*}{$\begin{array}{l}\text { Facilidade de uso } \\
\text { percebida }\end{array}$} & Aprender a usar o Banco Digital seria fácil pra mim & \multirow{6}{*}{$\begin{array}{l}\text { Davis, 1989; Pikkarainen } \\
\text { et al, } 2004\end{array}$} \\
\hline & Eu acho que seria fácil fazer o que eu quero pelo Banco Digital & \\
\hline & $\begin{array}{l}\text { Minha interação com o Banco Digital seria clara e } \\
\text { compreensível para mim }\end{array}$ & \\
\hline & $\begin{array}{l}\text { Eu acho que o Banco Digital seria flexível às minhas } \\
\text { necessidades }\end{array}$ & \\
\hline & $\begin{array}{l}\text { Será fácil pra mim desenv olver habilidades em usar o Banco } \\
\text { Digital }\end{array}$ & \\
\hline & No geral, eu acho que seria fácil utilizar o Banco Digital & \\
\hline \multirow{5}{*}{$\begin{array}{l}\text { Utilidade } \\
\text { percebida }\end{array}$} & $\begin{array}{l}\text { Usar o Banco Digital me permitiria utilizar os serviços do banco } \\
\text { mais rapidamente }\end{array}$ & \multirow{5}{*}{$\begin{array}{l}\text { Davis, 1989; Pikkarainen } \\
\text { et al, } 2004\end{array}$} \\
\hline & $\begin{array}{l}\text { Usar o Banco Digital para meus serviços bancários aumentaria } \\
\text { minha produtividade no trabalho e no dia a dia }\end{array}$ & \\
\hline & $\begin{array}{l}\text { Usar o Banco Digital aumentaria minha eficácia na utilização } \\
\text { dos serviços bancários, evitando erros }\end{array}$ & \\
\hline & $\begin{array}{l}\text { Usar o Banco Digital tornaria minha utilização dos serviços } \\
\text { bancários mais fácil }\end{array}$ & \\
\hline & $\begin{array}{l}\text { No geral, o Banco Digital seria util para eu utilizar os serviços } \\
\text { bancários }\end{array}$ & \\
\hline \multirow{2}{*}{$\begin{array}{l}\text { Satisfação } \\
\text { Percebida }\end{array}$} & Usar o Banco Digital seria agradável & \multirow{2}{*}{ Pikkarainen et al, 2004} \\
\hline & Usar o Banco Digital seria positivo & \\
\hline \multirow{5}{*}{$\begin{array}{c}\text { Segurança e } \\
\text { Privacidade } \\
\text { percebida }\end{array}$} & Usar o Banco Digital seria seguro financeiramente & \multirow{5}{*}{ Pikkarainen et al, 2004} \\
\hline & $\begin{array}{l}\text { Eu confio na habilidade do Banco Digital em proteger minha } \\
\text { priv acidade }\end{array}$ & \\
\hline & Eu confio na tecnologia que o Banco Digital usa & \\
\hline & $\begin{array}{l}\text { Eu confio no Banco Digital do mesmo jeito como confio no } \\
\text { banco comum }\end{array}$ & \\
\hline & Eu não estou preocupado com a segurança do Banco Digital & \\
\hline Renda & Estime sua renda familiar bruta mensal & Pikkarainen et al, 2004 \\
\hline Idade & Minha ldade é de $x$ anos & Pikkarainen et al, 2004 \\
\hline
\end{tabular}

Fonte: Elaboração própria a partir da revisão de literatura (2020)

As percepções de potenciais clientes de bancos digitais foram aferidas por meio de uma survey de amostra intencional e não probabilística, na cidade de Salvador, em março de 2019, com aplicação de 113 questionários, os quais foram preenchidos por respondentes, na presença de um dos pesquisadores, em três diferentes locais: em uma turma de alunos da pós-graduação em administração na UFBA, em uma turma de alunos de graduação em administração na UFBA, e com clientes de um Serviço de 
Atendimento ao Consumidor (SAC) localizado num shopping center da cidade. Desta forma, foram alcançadas pessoas que têm acesso à internet, e também as que não acessam a ferramenta. Buscou-se uma amostra com grande variação em termos de características demográficas (idade, renda e escolaridade). A presença dos pesquisadores nas entrevistas visou evitar que houvesse inconsistências ou aleatoriedade na resposta às perguntas do quadro.

Os entrevistados foram selecionados em amostragem por conveniência, que, de acordo com Hair et al (2016), envolve a seleção de elementos da amostra que estejam mais disponíveis e que podem oferecer as informações necessárias. Descartaram-se os indivíduos que já adotaram o banco digital, e se aplicou o instrumento apenas a pessoas que ainda não o utilizaram (clientes em potencial).

Para o tamanho da amostra (113 indivíduos), seguiu-se a orientação de Bentler (1995) para amostras não probabilísticas, que sugere que a amostra tenha tamanho mínimo de ao menos cinco vezes o número de parâmetros livres aferidos. O tamanho da amostra também segue a regra de Green (1991) que sugere uma amostra de tamanho total $50+8 K$, onde K é o número de variáveis independentes.

Os dados obtidos a partir da aplicação dos questionários foram tabulados e os procedimentos de tratamentos estatísticos dos mesmos foram realizados por intermédio do software SPSS V22. Houve apenas $1,46 \%$ de dados faltantes na amostra, um valor relativamente pequeno. As respostas marcadas como "não sei" e os dados faltantes foram tratados seguindo o tratamento aconselhado por Hair et al (2016). Assim, substituíram-se os valores faltantes por um valor médio. Segundo Hair et al (2016), essa abordagem permite minimizar a redução da variabilidade dos dados, caso outro tratamento mais simples fosse utilizado. 
Na análise dos resultados, foi efetuado o teste de multicolinearidade (VIF), que consiste no principal pressuposto a ser verificado na validação de regressões lineares (Hair et al, 2016).

\section{ANÁLISE E DISCUSSÃO DE RESULTADOS}

Esta seção apresenta os resultados da pesquisa e a discussão.

Os valores do índice de consistência interna do questionário, o Alpha de Cronbach, foram bastante satisfatórios e estão exibidos na tabela 3.

Tabela 3. Estatística de Confiabilidade

\begin{tabular}{c|c}
\hline Construto & Alpha de Cronbach \\
\hline Intenção de uso & 0,92 \\
\hline Utilidade Percebida & 0,95 \\
\hline Facilidade de Uso & 0,97 \\
\hline Satisfação Percebida & 0,98 \\
\hline $\begin{array}{c}\text { Segurança e Privacidade } \\
\text { Percebidas }\end{array}$ & 0,89 \\
\hline
\end{tabular}

Fonte: Elaboração própria a partir dos dados da pesquisa, 2021

Na Tabela 4 percebe-se que a maior parte dos indivíduos pesquisados possui entre 20 e 39 anos, representando mais de $70 \%$ da amostra, que se caracteriza por um grupo de respondentes jovens. 5,3\% do total possui mais de 60 anos.

Tabela 4. Descrição da amostra por idade, em anos

\begin{tabular}{ccc}
\hline Faixa etária & $\mathbf{n}$ & \% \\
\hline menor que 20 & 6 & 5,3 \\
20 a 29 & 59 & 52,2 \\
30 a 39 & 22 & 19,5 \\
40 a 49 & 12 & 10,6 \\
50 a 59 & 8 & 7,1 \\
acima de 60 & 6 & 5,3 \\
\hline Total & 113 & 100 \\
\hline
\end{tabular}


Fonte: Elaboração própria a partir dos dados da pesquisa, 2020

O percentual de homens foi de $42 \%$ homens e o de mulheres $58 \%$. No total, foram 47 homens e 66 mulheres entrevistados (Figura 2).

Figura 2. Percentual da amostra por gênero

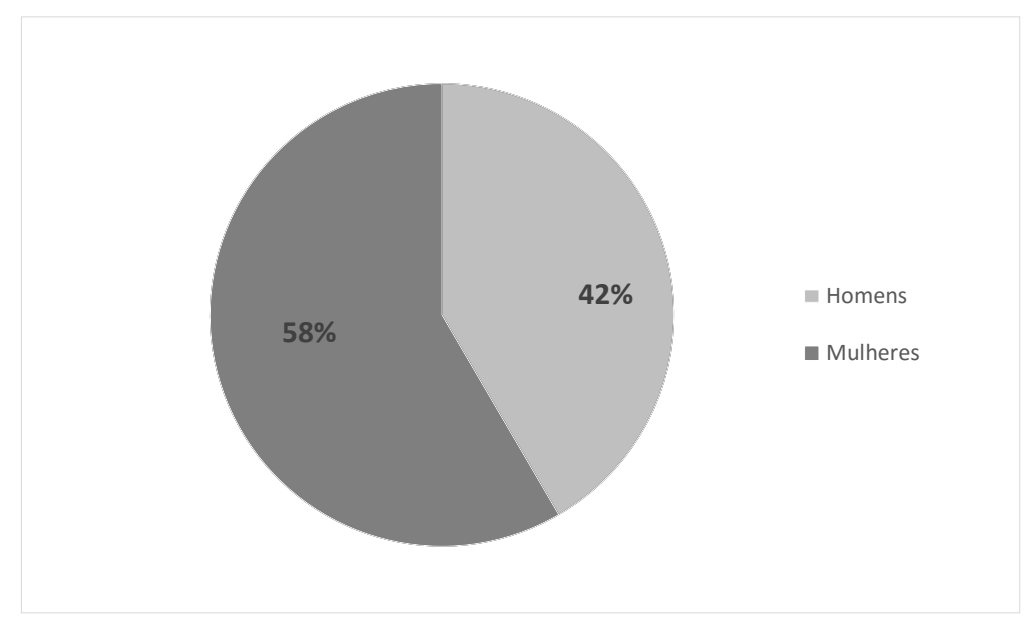

Fonte: Elaboração própria a partir dos dados da pesquisa, 2020

A renda familiar mensal variou entre $R \$ 350,00$ e $R \$ 70.000,00$, com média de $R \$ 6.235,95$. Essa variação da renda também contribuiu para testar sua influência sobre a intenção de uso e o alto valor médio encontrado pode estar associado aos entrevistados pós-graduandos presentes na amostra, representando um grupo com maior escolaridade, e provavelmente com maiores rendimentos familiares. Contudo, é possível observar que a maior parte dos respondentes possui renda mensal abaixo de $R \$ 5.000,00$, totalizando $62,8 \%$ dos pesquisados. O resumo dos dados pode ser observado na Tabela 5.

Tabela 5. Descrição da amostra por renda 


\begin{tabular}{lcc}
\hline Renda Familiar & $\mathbf{n}$ & \% \\
\hline menor que $\mathrm{R} \$ 1.000,00$ & 15 & 13,3 \\
De $\mathrm{R} \$ 1.000,00$ a $\mathrm{R} \$ 2.999,00$ & 33 & 29,2 \\
De $\mathrm{R} \$ 3.000,00$ a $\mathrm{R} \$ 4.999,00$ & 23 & 20,4 \\
De $\mathrm{R} \$ 5.000,00$ a $\mathrm{R} \$ 9.999,00$ & 22 & 19,5 \\
De $\mathrm{R} \$ 10.000,00$ a $\mathrm{R} \$ 19.999,99$ & 12 & 10,6 \\
acima de $\mathrm{R} \$ 20.000,00$ & 8 & 7,1 \\
\hline Total & $\mathbf{1 1 3}$ & 100 \\
\hline
\end{tabular}

Fonte: Elaboração própria a partir dos dados da pesquisa, 2020

A Tabela 6 traz evidências quanto às médias das avaliações para cada construto selecionado. A facilidade de uso recebeu média 4,0009, com desvio padrão 1,33403, em uma escala de 1 a 5, em que 5 significa que o respondente concorda totalmente com a afirmação. Isso sinaliza que os usuários em potencial do banco digital percebem como relativamente fácil a utilização dessa inovação bancária, o que pode estar relacionado à incorporação de novas tecnologias no cotidiano deles, como o uso frequente do celular para comunicação, ou na operacionalização dos aplicativos de banco, utilizados pelos clientes dos bancos tradicionais.

Tabela 6. Média e desvio padrão dos constructos

\begin{tabular}{l|r|r}
\hline \multicolumn{1}{c|}{ Variável } & \multicolumn{1}{c|}{ Média } & \multicolumn{1}{c}{$\begin{array}{c}\text { Desvio } \\
\text { padrão }\end{array}$} \\
\hline INTENCAO USO & 3,8527 & 1,33403 \\
\hline $\begin{array}{l}\text { UTILIDADE } \\
\text { PERCEBIDA }\end{array}$ & 3,8904 & 1,08733 \\
\hline FACILIDADE USO & 4,0009 & 1,15465 \\
\hline $\begin{array}{l}\text { SATISFACAO } \\
\text { PERCEBIDA }\end{array}$ & 3,9955 & 1,24731 \\
\hline SEGURANCA & 2,9406 & 1,03909 \\
PRIVACIDADE & 32,0973 & 13,08486 \\
\hline IDADE & 6235,955 & 9255,3279 \\
\hline RENDA & $\mathrm{n}=113$
\end{tabular}

Fonte: Elaboração própria a partir dos dados da pesquisa, 2020 
Ainda sobre a Tabela 6, observa-se que a segurança e privacidade obteve média 2,9406, com desvio padrão 1,03909, aproximando-se mais da proposição "discordo totalmente" do que de "concordo totalmente". A intenção de uso apresentou média 3,8527 e desvio padrão 1,33403 (relativamente alto), apresentando variação relativamente alta quanto à concordância e discordância nas afirmações. Esse item afirmava a pretensão em utilizar o banco digital no futuro e sua média tende a uma concordância. A utilidade percebida obteve média 3,8904, e um desvio padrão de 1,08733, o que revela uma maior tendência a concordar com as afirmações sobre a identificação de utilidade do banco digital para os pesquisados. Desta forma, houve uma tendência, na média, de os respondentes identificarem o banco digital como útil a suas atividades bancárias no cotidiano futuro. A satisfação percebida teve média de 3,9955 com desvio padrão de 1,24731. Esse valor aproxima-se da concordância com a afirmação sobre a percepção de que, na oportunidade de utilizar o banco digital, ele proporcionaria satisfação na utilização, numa experiência mais agradável e positiva. A análise da regressão poderá trazer mais evidências para a avaliação desses resultados.

Foi utilizada a técnica estatística de regressão linear múltipla com o intuito de verificar se os constructos independentes utilidade percebida, facilidade de uso, satisfação percebida e segurança e privacidade, bem como as variáveis idade e renda tinham influência significativa sobre o constructo dependente intenção de uso. Os resultados são apresentados a seguir.

As medidas gerais de adequação, apresentadas na Tabela 7, indicam que o modelo proposto apresenta um bom ajuste aos dados da amostra, considerando os valores de alfa e do diagnóstico de colinearidade previstos na literatura (Hair, 2017). O coeficiente de determinação ajustado (R2) apresentou valor 0,583, mostrando que a regressão possui poder explicativo de 58,3\%. O teste $F$ demonstra a existência de uma associação entre a 
intenção de uso e o conjunto de fatores explicativos do modelo de regressão.

Com relação aos parâmetros estimados do modelo, verificou-se que, dos sete fatores selecionados para o mesmo, dois não apresentaram valores significativos (teste †), não sendo possível obter conclusões sobre as observações propostas no estudo. Os fatores facilidade de uso e idade, não mostraram correlação significativa com a intenção de uso com certeza mínima de 95\% (valor-p abaixo de 0,05), como recomenda a literatura (Hair, 2017). Sendo assim, não é possível confirmar as hipóteses relacionadas a esses dois fatores.

Apesar de haver muitas evidências na literatura da relevância e efeito da "facilidade de uso percebida" sobre a "intenção de uso do internet banking e mobile banking" (Pikkarainen et al, 2004; Cheng, Lam \& Yeung, 2006; Fernades \& Awamleh, 2006; Lee, 2009; Laukkanen, 2016; George, 2018), essa correlação não apresentou significância para o presente estudo. Contudo, esse resultado coincide com o encontrado nos estudos de Malaquias e Hwang (2019) sobre aceitação do mobile banking no Brasil e EUA, o trabalho de Baptista e Oliveira (2015) sobre aceitação do mobile banking em países africanos, e Oliveira et al. (2014) em Portugal, em que o fator facilidade de uso percebida também não teve efeito significante sobre o fator dependente intenção de uso. Baptista e Oliveira (2015) argumentam que o alto nível de uso de celulares em Portugal pode ter influenciado na baixa significância da "facilidade de uso percebida", demandando pouco esforço para a aceitação do mobile banking. Entende-se que a maior difusão do uso do mobile banking aqui no Brasil e uma possível maior adesão dos entrevistados a esse serviço fornecido pelos seus bancos também tenha influenciado na percepção dos potenciais usuários sobre uma possível facilidade no uso do banco digital. Apesar disso, Malaquias e Hwang (2019) defendem que o constructo facilidade de uso parece continuar sendo um fator importante para melhorar a aceitação dessa tecnologia. Desta forma, 
com base nos resultados apresentados, não foi possível confirmar a hipótese 1 que afirmava que "a percepção de facilidade de uso tem efeito positivo na intenção de uso do banco digital".

A falta de significância da variável idade para a amostra deste estudo também é semelhante ao encontrado no estudo de Malaquias e Hwang (2019). Os autores justificaram a ausência de relação significativa entre a idade e a variável dependente pelo fato de sua amostra ser composta principalmente por participantes relativamente jovens, já que a pesquisa deles foi realizada apenas com estudantes de graduação. Tal justificativa pode ser válida também para explicar a falta de significância dessa variável para a amostra deste estudo, pois, apesar da tentativa de obter dispersão nas idades dos entrevistados, houve uma maior concentração de jovens (mais da metade dos pesquisados tem até 29 anos). Assim, considerando os resultados apresentados, não é possível confirmar a hipótese 6 que afirmava que "a idade tem um efeito negativo na intenção de uso do banco digital".

A Tabela 7 indica, para a amostra pesquisada, que os constructos utilidade percebida (coeficiente padronizado 0,271); satisfação percebida (coeficiente padronizado 0,318); segurança e privacidade (coeficiente padronizado 0,253); e a variável renda (coeficiente padronizado 0,116) têm impacto estatisticamente significativo sobre a intenção de uso do banco digital.

Tabela 7. Modelo estimado 


\begin{tabular}{|c|c|c|c|c|c|}
\hline \multirow{2}{*}{ Modelo } & \multirow{2}{*}{\begin{tabular}{|c}
$\begin{array}{c}\text { Coeficientes } \\
\text { padronizados }\end{array}$ \\
Beta
\end{tabular}} & \multirow{2}{*}{$t$} & \multirow{2}{*}{ P-value } & \multicolumn{2}{|c|}{$\begin{array}{l}\text { Estatísticas de } \\
\text { colinearidade }\end{array}$} \\
\hline & & & & $\begin{array}{c}\text { Tolerânc } \\
\text { ia }\end{array}$ & VIF*** \\
\hline (Constante) & 1,079 & 1,509 & 0,134 & & \\
\hline $\begin{array}{l}\text { UTILIDADE } \\
\text { PERCEBIDA }\end{array}$ & 0,271 & 2,553 & $0,012^{*}$ & 0,331 & 3,022 \\
\hline $\begin{array}{l}\text { FACILIDADE } \\
\text { DE USO } \\
\text { PERCEBIDA }\end{array}$ & 0,035 & 0,221 & 0,826 & 0,147 & 6,794 \\
\hline $\begin{array}{l}\text { SATISFACAO } \\
\text { PERCEBIDA }\end{array}$ & 0,318 & 1,972 & $0,050^{*}$ & 0,144 & 6,956 \\
\hline $\begin{array}{l}\text { SEGURANCA } \\
\text { PRIVACIDADE }\end{array}$ & 0,253 & 2,449 & $0,016^{*}$ & 0,35 & 2,854 \\
\hline$\overline{I D A D E}$ & $-0,105$ & $-1,152$ & 0,252 & 0,448 & 2,23 \\
\hline RENDA* & 0,116 & 1,676 & $0,097^{* *}$ & 0,773 & 1,293 \\
\hline
\end{tabular}

$R 2=0,583$ Teste $F$ do modelo de regressão $F=18,370$ com nível de confiança $a=0,000$ *Significante para $a<0,05$

**Significante para $a<0,1$

***Todos os valores de VIF (DIAGNOSTICO DE MULTICOLINEARIDADE) foram abaixo de 10, indicando que não há problemas na amostra (Hair, 2017).

Fonte: Elaboração própria a partir dos dados da pesquisa, 2020

A utilidade percebida, que mede o nível em que um indivíduo acredita que o uso de um determinado sistema irá aumentar o seu desempenho no trabalho (Davis, 1986), foi considerado um constructo relevante para a intenção de uso do banco digital, assim como consta nos estudos de Baptista e Oliveira (2015), Malaquias e Hwang (2019), Santouridis e Kyritsi (2014) e Pinkkarainen et al (2004) para tecnologias de mobile banking e internet banking. A hipótese 2 de que "a percepção de utilidade tem um efeito positivo na intenção de uso do Banco Digital" pôde ser confirmada, seguindo os pressupostos estabelecidos na literatura. Pode-se deduzir que a percepção dos respondentes de que o banco digital venha a ser útil no seu cotidiano pode aumentar as chances de uso ou a possibilidade de maior utilização do serviço no futuro. Essa evidência sinaliza que, ao desenvolverem a publicidade, os gestores dos bancos digitais deveriam evidenciar a utilidade de seus serviços para seus potenciais clientes. 
A percepção de satisfação foi também um constructo considerado significante para explicar a aceitação do banco digital. Segundo Davis, Bagozzi e Warshaw (1992), a percepção de satisfação trata do nível em que a atividade de usar um computador é percebida como agradável por si só. O resultado encontrado para a amostra deste estudo se assemelha aos estudos de Pikkarainen et al (2004) e Santouridis e Kyritsi (2014). Desta forma, foi possível confirmar a hipótese 3 que defendia, com base na literatura, que "a percepção de satisfação tem um efeito positivo na intenção de uso do banco digital".

A hipótese 4 sobre o constructo percepção de segurança e privacidade também foi aceita, confirmando que "a percepção de segurança e privacidade tem um efeito positivo na intenção de uso do banco digital.". Associado à percepção de risco e à confiança que o usuário possui sobre a tecnologia, foi possível considerar significante esse constructo, o que corrobora com o encontrado na literatura (Malaquias \& Hwang, 2016; Laforet \& Li, 2005; Fonseca, 2014). A percepção de risco foi o fator mais relevante no estudo de Cruz et al (2010) para a aceitação do mobile banking em sua amostra para o Brasil, a principal barreira de aceitação do mobile banking na China (Laforet \& Li, 2005) e em diversos países integrantes da União Européia (Fonseca, 2014). Assim, é importante que os potenciais usuários do banco digital percebam que seus dados estão seguros e protegidos e que suas informações bancárias estejam livres de ameaças virtuais. Maior percepção de segurança e privacidade aumenta a intenção de uso do banco digital. Isso indica que os bancos digitais que visem atrair clientes devem considerar fortalecer seus sistemas de segurança contra invasões e divulgar seus investimentos em tecnologias de proteção de dados aos seus acionistas e clientes. Deve também ser um fator explorado na confecção de campanhas publicitárias e nas redes sociais, garantindo a percepção de que seus sistemas são seguros. 
Quanto às variáveis demográficas, apenas a hipótese 5, "clientes com maior renda familiar tem maior intenção de uso do banco digital" foi estatisticamente significante e relevante para o modelo, embora tenha sido confirmada com menor grau de certeza, com alfa $<0,1$. A inclusão dessa variável trouxe complementaridade à capacidade explicativa do modelo e contribui para as evidencias encontradas na literatura (Darian, 1987; Venkatraman, 1991; Karjalouto, Mattila \& Pento, 2002). Assim como apontado em estudos anteriores sobre aceitação do internet banking (Karjalouto, Mattila \& Pento, 2002; Mauter, 2005), uma maior renda está associada ao uso do banco pela internet e pelo mobile banking. Como defende Meuter (2005), o aumento da renda poderia também aumentar as oportunidades de acesso a dispositivos mais atualizados (computadores e dispositivos móveis, por exemplo) e fornecer motivações para economia de tempo e praticidade no relacionamento com o banco, o que pode justificar a maior intenção de uso por indivíduos com maior renda. Desta forma, a hipótese 5 que defendia que "clientes com maior renda familiar tem maior intenção de uso do banco digital" foi confirmada. Esse resultado pode ser utilizado pelos bancos através na maior atenção ao público de alta renda, oferecendo serviços tecnológicos diferenciados, apresentando o banco digital com um modelo segmentado, oferecendo para o público de alta renda produtos e serviços diferenciados, que ofereçam maior valor agregado, associado aos fatores apresentados anteriormente.

A tabela 8 apresenta uma síntese dos resultados obtidos, e uma comparação com os resultados de outros artigos previamente citados.

Tabela 8. Síntese dos resultados das hipóteses testadas 
Fatores determinantes da aceitação de mercado da tecnologia do banco digital no contexto brasileiro

\begin{tabular}{|c|c|c|c|c|}
\hline Variável & Hipótese & Confirmam a Hipótese & $\begin{array}{l}\text { Não confirmam a } \\
\text { hipótese }\end{array}$ & $\begin{array}{l}\text { Resultado encontrado } \\
\text { no estudo }\end{array}$ \\
\hline $\begin{array}{l}\text { Percepção de } \\
\text { Facilidade de Uso } \\
\text { (PEOU) }\end{array}$ & $\begin{array}{l}\text { HI: A percepção de facilidade de } \\
\text { uso tem efeito positivo na } \\
\text { intenção de uso do banco digital. }\end{array}$ & $\begin{array}{l}\text { Pikkarainen et al, 2004; Cheng, Lam \& } \\
\text { Yeung, 2006; Fernades \& Awamleh, } \\
\text { 2006; Lee, 2009; Laukkanen, 2016; } \\
\text { George, } 2018 .\end{array}$ & $\begin{array}{l}\text { Malaquias \& Hwang, } \\
\text { 2019; Baptista \& } \\
\text { Oliveira, 2015; Oliveira } \\
\text { et al., 2014. }\end{array}$ & $\begin{array}{l}\text { Hipótese não } \\
\text { confirmada. }\end{array}$ \\
\hline $\begin{array}{l}\text { Percepção de Utilidade } \\
\text { (PU) }\end{array}$ & $\begin{array}{l}\text { H2: A percepção de utilidade tem } \\
\text { um efeito positivo na intenção de } \\
\text { uso do banco digital. }\end{array}$ & $\begin{array}{l}\text { Kishore \& Sequeira, 2016; Baptista \& } \\
\text { Oliveira, 2015; Ha et al, } 2012 .\end{array}$ & - & Hipótese confirmada \\
\hline $\begin{array}{l}\text { Percepção de } \\
\text { Satisfação }\end{array}$ & $\begin{array}{l}\text { H3: A percepção de satisfação } \\
\text { tem um efeito positivo na intenção } \\
\text { de uso do banco digital pelos } \\
\text { consumidores. }\end{array}$ & $\begin{array}{l}\text { Konradt, Christophersen \& Schaeffer- } \\
\text { Kuelez, 2006; Pikkarainen et al, 2004; } \\
\text { Santouridis e Kyritsi, } 2014 .\end{array}$ & - & Hipótese confirmada. \\
\hline $\begin{array}{l}\text { Percepção de } \\
\text { Segurança e } \\
\text { Privacidade }\end{array}$ & $\begin{array}{l}\text { H4: A percepção de segurança e } \\
\text { privacidade tem um efeito } \\
\text { positivo na intenção de uso do } \\
\text { banco digital pelos consumidores. }\end{array}$ & $\begin{array}{l}\text { Laforet \& Li, 2005; Fonseca, 2014; } \\
\text { Bhatiasevi, } 2016 .\end{array}$ & - & Hipótese confirmada. \\
\hline \multirow{2}{*}{$\begin{array}{l}\text { Variáveis } \\
\text { sóciodemográficas }\end{array}$} & $\begin{array}{l}\text { H5: Clientes com maior renda } \\
\text { familiar têm maior intenção de uso } \\
\text { do banco digital }\end{array}$ & $\begin{array}{l}\text { Karjalouto, Mattila \& Pento, 2002; } \\
\text { Mauter, } 2005 .\end{array}$ & - & Hipótese confirmada. \\
\hline & $\begin{array}{l}\text { H6: A idade tem um efeito } \\
\text { negativo na intenção de uso de } \\
\text { banco digital. }\end{array}$ & $\begin{array}{l}\text { Harrison \& Rainer, 2012; Wang, Wu \& } \\
\text { Wang, 2009; Mohammadi, } 2015 .\end{array}$ & $\begin{array}{l}\text { Malaquias \& Hwang, } \\
2019 .\end{array}$ & $\begin{array}{l}\text { Hipótese não } \\
\text { confirmada. }\end{array}$ \\
\hline
\end{tabular}

Fonte: Elaboração própria a partir dos dados da pesquisa, 2020

A Figura 3 apresenta o modelo final estruturado a partir da estimação dos parâmetros e do resultado das hipóteses testadas, relacionando a variável dependente intenção de uso do banco digital com os constructos e variáveis independentes considerados estatisticamente significativos na estimação da regressão.

Figura 3. Modelo empírico resultante da pesquisa 


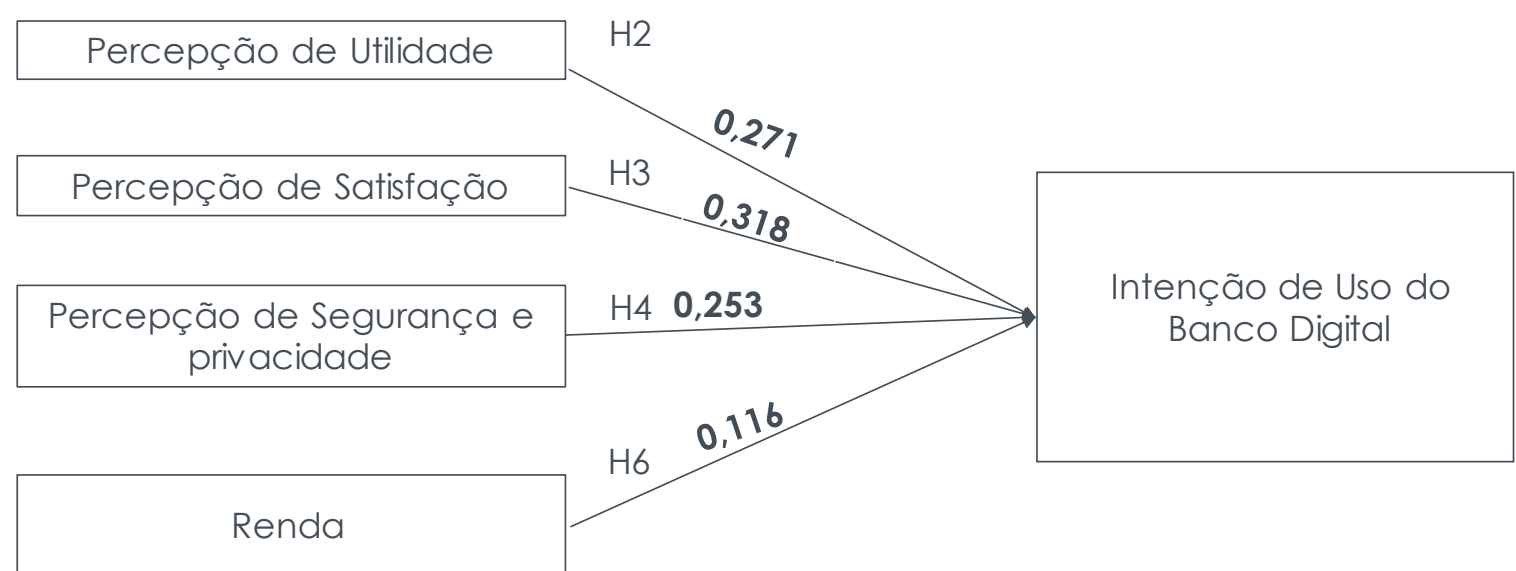

Fonte: Elaboração própria a partir dos dados da pesquisa, 2020

\section{CONCLUSÕES}

O trabalho buscou, de forma pioneira, estudar os fatores determinantes da aceitação da tecnologia dos bancos digitais pelos potenciais consumidores no Brasil à luz do modelo TAM, adicionando novas variáveis explicaticas e demográficas, derivadas da literatura sobre o tema. $\bigcirc$ contexto atual de uso de tecnologias digitais foi considerado relevante como um fator contribuinte para a mudança dos hábitos dos consumidores e para uma expectativa de maior aceitação, em comparação com a primeira experiência da tecnologia implantada nos anos 2000 no Brasil. Foi feita uma avaliação empírica com 113 indivíduos na cidade de Salvador (BA), por intermédio da aplicação de questionário construído a partir do modelo conceitual de análise desenvolvido pelos autores deste trabalho. Os resultados aqui colhidos, e sua análise, contribuem para a literatura brasileira, que é relativamente escassa, focada no uso e aceitação de tecnologias digitais, e em especial as tecnologias auxiliadas pela internet, em países em desenvolvimento. Conforme foi demonstrado na tabela 8, o estudo confirma parcialmente algumas das conclusões de estudos semelhantes efetuados no contexto brasileiro e de outros países (Baptista e Oliveira, 2015; Malaquias e Hwang, 2019; Santouridis e Kyritsi, 2014; Pinkkarainen et al., 2004; Malaquias \&Hwang, 2016; Laforet \& Li, 2005; Fonseca, 2014; Cruz et al, 2010; Laforet \& Li, 2005; Karjalouto, Mattila \& Pento, 2002; Mauter, 2005). 
Do ponto de vista gerencial, os resultados encontrados apontam para os fatores relevantes a serem inseridos em campanhas publicitárias e de marketing que busquem aproximação com o mercado consumidor brasileiro neste segmento.

Foram identificadas como mais relevantes, para a amostra pesquisada, as variáveis dos constructos utilidade percebida, satisfação percebida, e segurança e privacidade, além da variável renda, impactando a intenção de uso do potencial cliente dos produtos bancários. Essas evidências reforçam as observações anteriores encontradas na literatura.

Apesar dos resultados satisfatórios da pesquisa, já que um número considerável de suas hipóteses foi confirmada, algumas limitações devem ser apontadas. A pesquisa dedicou-se a mensurar a amostra de forma não probabilística e por conveniência. Portanto trata-se de uma amostra pequena e enviesada. Desta forma, não é possível generalizar os resultados obtidos neste estudo. Outra limitação é que o levantamento de dados da pesquisa se concentrou na região de Salvador, o que limita também a possibilidade de generalizações para o país, por não ser possível considerar Salvador uma localidade suficientemente representativa para os hábitos e costumes a nível nacional. A terceira limitação é o tamanho e diversidade da amostra. Apesar da tentativa de buscar diversidade dos dados, realizando a pesquisa em diferentes locais, não foi possível obter uma amostra bastante diversificada que permitisse captar diferentes percepções (por idade, por exemplo). Trabalhos futuros que busquem explorar o tema podem dedicar-se a explorar tais limitações, expandindo o estudo para o âmbito nacional e realizando a coleta dos dados através de uma amostra probabilística, possibilitando a generalização dos resultados. É importante salientar que a grande maioria dos estudos empíricos sobre aceitação de tecnologias bancárias não é baseado em amostra probabilística e aleatória. Dentre a literatura selecionada para a definição das hipóteses, apenas os 
estudos de Laforet e Li (2005) e Cheng, Lam e Yeung(2006) realizaram estudos com seleção aleatória dos participantes.

Resta destacar que embora o estudo apresente as limitações acima referidas, sua metodologia poderá ser replicada em contextos a salvo das referidas limitações, trazendo mais contribuições acadêmicas e gerenciais sobre os fatores que influenciam a intenção de uso de bancos digitais.

\section{REFERÊNCIAS}

Alt, R.,, Puschmann, T. (2012). The rise of customer-oriented banking electronic markets are paving the way for change in the financial industry. Electronic Markets, 22(4), 203-2015. https://doi.org/10.1007/s1 2525-012-0106-2

Banco Central Do Brasil (2016). Resolução n4.480 de 25 de abril de 2016. Sisbacen. Seção 1, p. 3.

Banco Central Do Brasil (2017). Global Findex - O Brasil na comparação internacional.

Disponível

em:

<https://www.bcb.gov.br/Nor/relcidfin/docs/art4_comparacao_internacional .pdf> Acesso em 27 out 2020.

Baptista, G., Oliveira, T. (2015). Understanding mobile banking: The unified theory of acceptance and use of technology combined with cultural moderators. Computers in Human Behavior, v. 50, p. 418430.https://doi.org/10.1016/j.chb.2015.04.024

Bentler, P. M. (1995). EQS structural equations program manual. Encino, CA: Multivariate software.

Bhatiasevi, V. (2016). An extended UTAUT model to explain the adoption of mobile banking. Information Development, v. 32, n. 4, p. 799-814.: https://doi.org/10.1177/0266666915570764 
Bijker, W. E., Law, J. (eds.) (1992). Shaping Technology/Building Society: Studies in Sociotechnical Change. Cambridge, Massachusetts: MIT Press, p. 75-104.

Braun, M. T. (2013). Obstacles to social networking website use among older adults. Computers in human behavior, 29(3), 673680.https://doi.org/10.1016/j.chb.2012.12.004

Carvalho, A. P. A. F. (2020). Dos Bancos Tradicionais aos Digitais: quais riscos corporativos os bancos brasileiros enfrentam ao investirem em Fintechs?. Caderno Virtual, 1(46).

Charness, N., Boot, W. R. (2016). Technology, gaming, and social networking. In Handbook of the Psychology of Aging (pp. 389-407). Academic Press.

Cheng, T. E., Lam, D. Y., \& Yeung, A. C. (2006). Adoption of internet banking: an empirical study in Hong Kong. Decision support systems, 42(3), 1558-1572. https://doi.org/10.1016/j.dss.2006.01.002

Chuang, L. M., Liu, C. C., Kao, H. K. (2016). The adoption of fintech service: TAM perspective. International Journal of Management and Administrative Sciences, 3(7), 1-15.

Claessens, S., Laeven, L. (2005). Financial dependence, banking sector competition, and economic growth. Journal of the European Economic Association, v. 3, n. 1, p. 179-207.https://doi.org/10.1162/1542476053295322

Clerides, S., Delis, M. D., Kokas, S. (2015). A new data set on competition in national banking markets. Financial Markets, Institutions \& Instruments, v. 24, n. 2-3, p. 267-311.https://doi.org/10.1111/fmii.12030

Cruz, P., Neto, L. B. F., Munoz-Gallego, P., \& Laukkanen, T. (2010). Mobile banking rollout in emerging markets: evidence from Brazil. The International Journal of bank marketing, 28(5), 342-371. https://doi.org/10.1108/02652321011064881 
Cook, S. (2017) Selfie banking: is it a reality?. Biometric Technology Today, v. 2017, n. 3, p.9-11.https://doi.org/10.1016/S0969-4765(17)30056-5

Davis, F.D. (1986). A Technology acceptance model for empirically testing new end-user information systems: Theory and results. MA, USA: Massachussetts Institute of Technology. .

Davis, F. D. (1989). Perceived usufulness, perceived ease of use, and user acceptance of information technology. MIS Quarterly, Minneapolis (MN), v.13, n.3, p.319-339.https://doi.org/10.2307/249008

Davis, F.D., Bagozzi, R.P., Warshaw, P.R.(1992). Extrinsic and intrinsic motivation to use computers in the workplace, Journal of Applied Social Psychology, Vol. 22 No. 14, pp. 1111-32.https://doi.org/10.1111/j.15591816.1992.tb00945.x

Demirguc-Kunt, A., Klapper, L., Singer, D., Ansar, S., \& Hess, J. (2017). The Global Findex Database: Measuring Financial Inclusion and the Fintech Revolution. World Bank Group. International Bank for Reconstruction and Development/The World Bank, Washington DC.

Diniz, E. H. (2004) Cinco décadas de automação. GV-executivo, [S.I.], v. 3, n. 3, p. 55-60. https://doi.org/10.12660/gvexec.v3n3.2004.34691

Faria, A. F., Maçada, A. C. G. (2011). Impacto dos investimentos em TI no resultado operacional dos bancos brasileiros. RAE-Revista de Administração de Empresas, 51 (5), 440-457.

Filgueiras, A. R.F. \& DAmorim, R. S. (2019). Percepção da Qualidade em Serviços: Associação com o Modelo de Excelência em Gestão-MEG. Marketing \& Tourism Review, 4(1).https://doi.org/10.29149/mtr.v4i1 .4786

FINTECHLAB (2020). Edição 2020 do Radar Fintechlab detecta 270 novas fintechs em ano. Disponível em: <http://fintechlab.com.br/index.php/2020/08/25/edicao-2020-do-radarfintechlab-detecta-270-novas-fintechs-em-um-ano/> Acesso em: 29 out 2020 
Fonseca, J. R.S. (2014). E-banking culture: A comparison of EU 27 countries and Portuguese case in the EU 27 retail banking context, Journal of Retailing and Consumer Services, Vol. 21, p 708716.https://doi.org/10.1016/j.jretconser.2014.05.006

Gelman, A. and Hill, J. (2007), Data Analysis Using Regression and Multilevel/Hierarchical Models, Cambridge University Press, New York, NY.

George, A. (2018). Perceptions of Internet banking users-a structural equation modelling (SEM) approach. IIMB Management Review, v. 30, n. 4, p. 357-368.https://doi.org/10.1016/j.iimb.2018.05.007

Green, S.B. (1991).How many subjects does it take to do a regression analysis, Multivariate Behavioral Research, Vol. 26 No. 3, pp. 499-510. https://doi.org/10.1207/s15327906mbr2603_7

Hair Jr, J. F., Hult, G. T. M., Ringle, C., \& Sarstedt, M. (2016). A primer on partial least squares structural equation modeling (PLS-SEM). Sage publications.

Hair, J. (2005). Fundamentos de métodos de pesquisa em administração. Bookman Companhia $5 \mathrm{Ed}$.

Hanafizadeh, P., Keating, B.W., Khedmatgozar, H. R. (2014). A systematic review of Internet banking adoption. Telematics and informatics, v. 31, n. 3, p. 492-510.https://doi.org/10.1016/j.tele.2013.04.003

Hernandez, J. M. D. C., \& Mazzon, J. A. (2008). Um estudo empírico dos determinantes da adoção de internet banking entre não usuários brasileiros. Revista de Administração Contemporânea, 12(SPE), 939.https://doi.org/10.1590/S1415-65552008000500002

Im, I., Hong, S., \& Kang, M. S. (2011). An international comparison of technology adoption: Testing the UTAUT model. Information \& management, 48(1), 1-8. https://doi.org/10.1016/j.im.2010.09.001 
Jha, A. K., Bose, I. (2016). Innovation research in information systems: A commentary on contemporary trends and issues. Information \& Management, 53(3), 297-306.https://doi.org/10.1016/j.im.2015.10.007

Jornal de Negócios (2019): Unibanco_ acaba_com_operacoes do bancolnet. Disponível em: $\quad<\quad$ https:/l www.jornaldenegocios.pt/empresas/detalhe/unibanco__ acaba_com_ operacoes_do_bancolnet > Acesso em: 6 dez 2019.

Karjaluoto, H., Mattila, M. and Pento, T. (2002). Factors underlying attitude formation towards online banking in Finland. International Journal of Banking $\begin{array}{llllll}\text { Marketing, } & \text { Vol. } & 20 & \text { No. } & 6, & \text { pp. }\end{array}$ 261-72.https://doi.org/10.1108/02652320210446724

Kovalczyk, N. (2017). Retorno sobre Investimento em TI com ênfase em ERP. Revista Interdisciplinar de Tecnologias e Educação, 3(1).

Konradt, U., Christophersen, T., Schaeffer-Kuelz, U. (2006). Predicting user satisfaction, strain and system usage of employee self-services. International Journal of Human-Computer Studies, v. 64, n. 11, p. 11411153.https://doi.org/10.1016/j.jijhcs.2006.07.001

Kotler, P., Kartajaya, H., Setiawan, I. (2017). Marketing 4.0: do tradicional ao digital. Rio de janeiro: Sextante.

Laforet, S., Li, X. (2005). Consumers Attitudes to Online and Mobile Banking in China. International Journal of Bank Marketing, 23, 362380.https://doi.org/10.1 108/02652320510629250

Larsson, A., Viitaoja, Y. (2017).Building customer loyalty in digital banking: A study of bank staff's perspectives on the challenges of digital CRM and loyalty. International Journal of Bank Marketing, v. 35, n. 6, p. 858-877. https://https://doi.org/10.1108/IJBM-08-2016-0112

Laukkanen, T. (2016). Consumer adoption versus rejection decisions in seemingly similar service innovations: The case of the Internet and mobile 
banking. Journal of Business Research, v. 69, n. 7, p. 24322439.https://doi.org/10.1016/j.jbusres.2016.01.013

Lee, M. C. (2009). Factors influencing the adoption of internet banking: An integration of TAM and TPB with perceived risk and perceived benefit. Electronic commerce research and applications, 8(3), 130 141.https://doi.org/10.1016/j.elerap.2008.11.006

Lee, Y., Kozar, K.A., Larsen, K.R (2003). The technology acceptance model: Past, present, and future. Communications of the Association for Information Systems, Vol. 12 p. 752-780.Https://doi.org/10.17705/1CAIS.01250

Malaquias, R. F., Hwang, Y.(2016).An empirical study on trust in mobile banking: A developing country perspective. Computers in Human Behavior, v. 54, p. 453-461. https://doi.org/10.1016/j.chb.2015.08.039

Malaquias, R. F., Hwang, Y.(2019) Mobile banking use: A comparative study with Brazilian and U.S. participants, International Journal of Information $\begin{array}{llll}\text { Management, } & \text { Vol. } & \text { p. } & \text { 132-140. }\end{array}$ https://doi.org/10.1016/j.jijinfomgt.2018.10.004

Malhotra, N. (2012). Pesquisa de Marketing: uma orientação aplicada. 6 ed. Porto alegre: Bookman.

Mbama, C. I., Ezepue, P. O. (2018) Digital banking, customer experience and bank financial performance: UK customers' perceptions. International Journal of Bank Marketing, v. 36, n. 2, p. 230-255. https://doi.org/10.1 108/IJBM$11-2016-0181$

Neter, J., Kutner, M.H., Nachtsheim, C.J. and Wasserman, W. (1996), Applied Linear Statistical Models,Irwin, Chicago.

Oliveira, T., Faria, M., Thomas, M. A., \& Popovič, A. (2014). Extending the understanding of mobile banking adoption: When UTAUT meets TTF and ITM. International journal of information management, 34(5), 689-703. https://doi.org/10.1016/j.jijinfomgt.2014.06.004 
Pikkarainen, T., Pikkarainen, K., Karjaluoto, H., Pahnila, S. (2004). Consumer acceptance of online banking: an extension of the technology acceptance model. Internet research, 14 (3) (2004), pp. 224-235. https://doi.org/10.1108/10662240410542652

Pires, P. J., Da Costa Filho, B. A. (2008). Fatores do índice de prontidão à tecnologia (TRI) como elementos diferenciadores entre usuários e não usuários de internet banking e como antecedentes do modelo de aceitação de tecnologia (TAM). Revista de Administração Contemporânea, v. 12, n. 2, p. 429-4. https://doi.org/10.1590/S1415-65552008000200007

Ross, J., Beath, C., Sebastian, I. (2017) Digital \# Digital. Research Briefing, vol. XVII, no. 10. MIT Sloan Center for Information Systems Research, Cambridge, MA .

Santouridis, I., Kyritsi, M. (2014). Investigating the determinants of Internet banking adoption in Greece. Procedia Economics and Finance, v. 9, p. 501510. https://doi.org/10.1016/S2212-5671(14)00051-3

Shaikh, A. A., Karjaluoto, H. (2015). Mobile banking adoption: A literature review. Telematics and Informatics, v. 32, n. 1, p. 129142.https://doi.org/10.1016/j.tele.2014.05.003

Veiga, L.H. C., Oliveira, A. (2006). Diferenciação Horizontal e Poder de Mercado: Os Efeitos do E-Banking sobre as Tarifas Bancárias. Revista EconomiA. V.7, 365-393.

Venkatesh, V., Morris, M. G., Davis, G. B., Davis, F. D. (2003). User acceptance of information technology: Toward a unified view. MIS quarterly, 425-478. https://doi.org/10.2307/30036540

Venkatesh, V., Davis, F. D. (2000). A theoretical extension of the technology acceptance model: Four longitudinal field studies. Management science, v. 46, n. 2, p. 186-204. https://doi.org/10.1287/mnsc.46.2.186.11926

Vergara, S.C. (2013), Métodos De Pesquisa Em Administração, Atlas, São Paulo. 
Wang, Y.S., Wu, M.C., Wang, H.Y. (2009). Investigating the determinants and age and gender differences in the acceptance of mobile learning. British journal of educational technology, v. 40, n. 1, p. 92-118. https://doi.org/10.1111/j.1467-8535.2007.00809.x

Yin, R.K. (2011), Applications of Case Study Research, Sage, Washington, DC.

Yiu, C.S., Grant, K., Edgar, D. (2007). Factors affecting the adoption of Internet Banking in Hong Kong-implications for the banking sector. International journal of information management, v. 27, n. 5, p. 336351.https://doi.org/10.1016/j.jijinfomgt.2007.03.002 